\title{
Study of Organic Rankine Cycles with Zeotropic Mixture Working Fluids Applied on the Waste Heat Recovery System
}

\author{
Shengya Hou ${ }^{1, a}$, Wenping Zhang ${ }^{1, b}$, Jiachen $\mathrm{Ji}^{1, \mathrm{c}}$ andZiwei Zeng ${ }^{1, \mathrm{~d}}$ \\ ${ }^{1}$ Harbin Engineering University,Harbin,China \\ ahoushengya@hrbeu.edu.cn, bzhangwenping@hrbeu.edu.cn, \\ cjijiachen@hrbeu.edu.cndzengziwei@ hrbeu.edu.cn,
}

\begin{abstract}
Keywords: Organic Rankine Cycle; Zeotropic mixture; Comparative study; Influence factors Abstract. Taking good advantage of the diesel-exhaust with the Organic Rankine Cycle (ORC) System contributes to raising the thermal efficiency, saving fuel consumption and reducing the cost, since there is much energy carried by the diesel-exhaust. There come some problems on the match for the temperature of heat source when the ORC system uses pure fluids as working fluids, so we considered adopting zeotropic mixture working fluids to solve the problems and improving the comprehensive properties of thermodynamics. The zeotropic mixture performs better than the pure fluid at the thermal efficiency,exergy efficiency, net work and the expansion ratio in the regenerative cycle, while it has no superiority than the pure fluid in the basic process. The study of zeotropic mixture suggest that the higher the temperature of the heat source and the lower the temperature of the cold source is ,the higher cycle thermal efficiency and net work are. When taking cycle net work as target function, there is the optimal evaporation temperature and superheat degree. We should choose the suitable evaporation temperature first because its priority is higher than the superheat degree by comparing different influence factors on the cycle.
\end{abstract}

\section{Introduction}

Nowadays, the thermal efficiency of the most advanced two-stroke diesel engine has been close to $50 \%$, but there is still more than half of the fuel energy taken away by the exhaust gas and cooling water to the environment, which making not only environment damaged but energy wasted as well. At present, there is massive exhaust energy of two-stroke marine diesel engine left after supplying for the turbocharger, because the efficiency of exhaust turbocharger has been improved. The diesel only turns $49.3 \%$ of fuel energy into useful work, and the remaining $50.7 \%$ is not being used but discharged into the atmosphere in various forms. In order to maintain the normal operation of the ship, we need configuring the auxiliary diesel engines and auxiliary boilers to burn fuel to provide sufficient electricity and steam. Obviously, if the heat of the exhaust gas can be used to generate electricity, which can take the place of some auxiliary equipment, the effect of energy-saving and emission reduction can be reached. Thus, it is significant to take full recovery of the waste heat of the marine engine and the cooling water.

You-Rong $\mathrm{Li}^{[1]}$ found that the compositions of the mixtures have an important effect on the ORC system performance, which is associated with the temperature glide during the phase change of mixtures. Zhenhua Kang ${ }^{[2]}$ found that R245fa/R600a (0.9/0.1) was the most preferable mixture among the working fluids within the scope of his research. M. Chys ${ }^{[3]}$ found that the electricity production at optimal thermal power recuperation can be increased by $20 \%$ for the low temperature heat source. Jian Zhang ${ }^{[4]}$ found that the zeotropic mixture isopentane/R245fa (in a $0.7 / 0.3 \mathrm{~mol}$ fraction) performs best. Florian Heberle ${ }^{[5]}$ found that using mixtures can be adjusted to higher temperatures by adding a less volatile component. Baomin Dai ${ }^{[6]}$ found that $\mathrm{CO}_{2} / \mathrm{R} 41$ and $\mathrm{CO}_{2} / \mathrm{R} 32$ are suitable candidates for heat pump water heaters because of their high COP and low high-side pressure in comparison with those of a pure $\mathrm{CO}_{2}$ cycle. J.G. Andreasen ${ }^{[7]}$ found that an optimized ethane/propane mixture attains a $12.9 \%$ net power increase when the hot fluid inlet temperature is $120^{\circ} \mathrm{C}$ and a $11.1 \%$ net power increase when the hot fluid inlet temperature is $90^{\circ} \mathrm{C}$. 


\section{Establishment and Simulation of ORC system model}

The simple cycle includes an organic working fluid heat exchanger, an expander, a condenser and a pump. Fig. 1 is the schematic diagram of the process of ORC system.
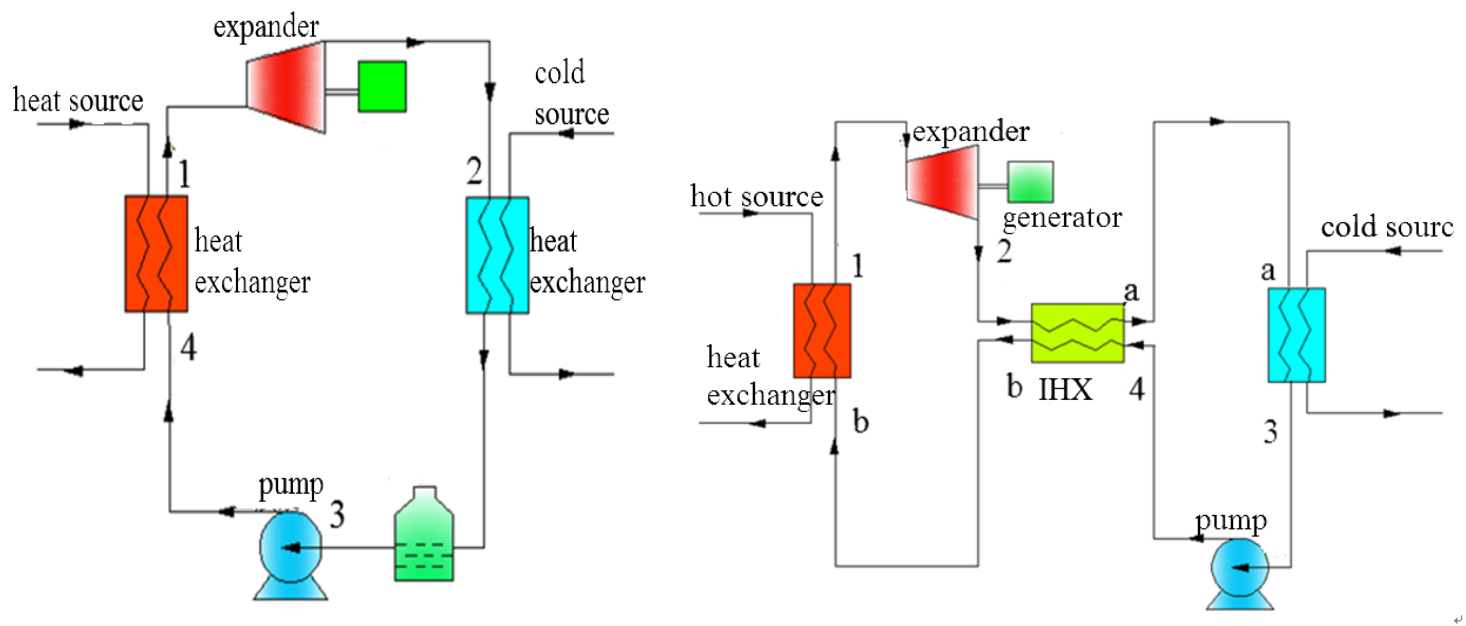

Fig.1. the Design of the cycle without IHX Fig.2. The Design of the cycle with IHX

Procedure 4-1: organic fluid is changed from the unsaturated state to the overheating or saturated state in the heat exchanger; Procedure 1-2: overheated or saturated steam of organic fluid expands and outputs power in the expander; Process 2-3: the exhausted steam outputs its heat to the cooling water in the condenser; Procedure 3-4: the organic fluid goes through the pump to raise its pressure, and then goes into the evaporator heat exchanger again, completing a cycle.

The system with IHX consists of the compressor, heat exchanger, expander and generator sets, condenser, and the regenerator as shown in the Fig2. The difference between the simple and the system with IHX is that the system with IHX can recover the energy from the expander outlet.

Fig 3 is an ORC system with IHX established in the ASPENPLUS. Wherein the pump B1 chooses ICON1 of BUMP module, defining the entropy efficiency of the pump as 0.85 . The expander B3 selects ICON2 of COMPR module, defining the entropy efficiency of the pump as 0.85.The exchanger B2 selects GEN-HT of HEATX module defining the difference between the inlet temperature of the heat and the outlet temperature of the cold as $20 \mathrm{~K}$. The condenser $\mathrm{B} 4$ selects HEATER module, defining the temperature at the outlet as $32{ }^{\circ} \mathrm{C}$.
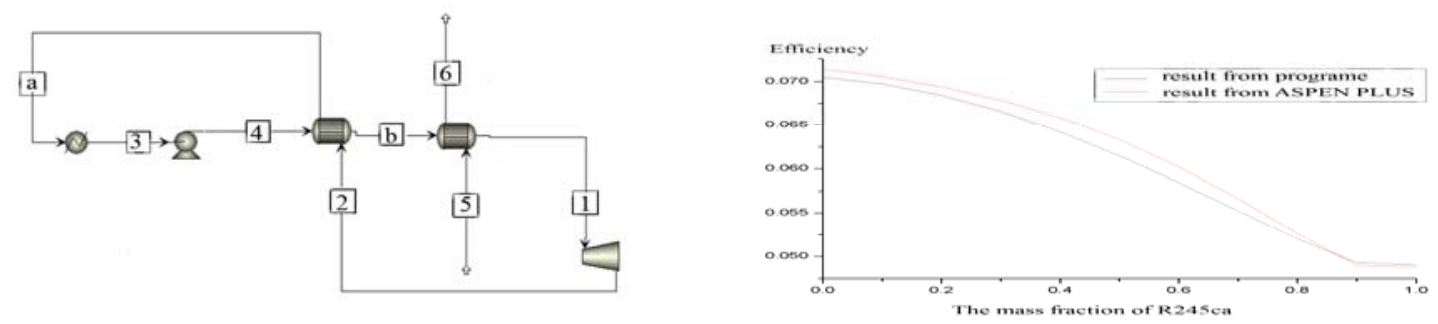

Fig.3. the heat recovery system

Fig.4. the Comparison of simulation results from refprop and ASPEN

The Fig.4 compares the results from REFPROP9.0 and the results from the ASPEN. The physical method uses PENG-ROB simulation. Just as the results shown by Fig.4.The difference between the result from program and the result from simulation is small, and the error is under $2 \%$, so the programmer simulation systems and the ASPEN simulation systems can be mutually verified, which is helpful in getting accurate conclusions.

\section{The comparative study between zeotropic and pure fluids}

As for the power cycle system of pure organic working fluid, the exergy loss of the evaporator is the highest, putting restrictions on the improvement of the efficiency and the net work of the cycle; and that's mainly because of the impact bias of the match between the heat source and the pure fluid, 
caused by the temperature difference of the pinch point. The temperature difference of the pinch point is the smallest difference during the Evaporator Process, appearing at the bubble point of the pure fluid. The temperature of the bubble point of the pure fluid is the same as the dew point; but the mixture fluid not the same, there is a temperature glide benefiting the match between the mixture and the heat sink a lot.

The $\mathrm{P}-\mathrm{H}$ diagram can directly reflect the relationship between the work and the heat during the cycle; besides, the $\mathrm{T}-\mathrm{S}$ diagram can intuitively reflect the match situation between the fluid and the heat source during the cycle; therefore, this paper gives the $\mathrm{T}-\mathrm{S}$ diagram and the $\mathrm{P}-\mathrm{H}$ chart of the pure refrigerant R227ea, R245ca and mixtures R227ea/R245ca (0.2/0.8). Figs 5, 6, 7 are the $\mathrm{P}-\mathrm{H}$ and T-S Fig of the pure refrigerants R227ea, R245ca and the mixed refrigerants R227ea/ R245ca $(0.2 / 0.8)$ in the basic cycle, setting the same heat source conditions: the heat source temperature as $140^{\circ} \mathrm{C}$, the temperature as $25^{\circ} \mathrm{C}$, while setting the temperature difference between the heat transfer process as $5^{\circ} \mathrm{C}$. According to the parameters of each state point in the cycle, we can draw the $\mathrm{P}-\mathrm{H}$ and $\mathrm{T}-\mathrm{S}$ diagrams in the cycle process. In the Fig, the basic cycle is surrounded by a blue line, the heat recovery process is surrounded by a red line, the pink line represents the heat transfer process, and the green line represents the condensation process.

The comparison between the $\mathrm{P}-\mathrm{H}$ pictures of the pure and mixed working substance suggests that the expansion ratio is lower which leads to the lower cost. Because the phase change process of the pure fluid in the condenser is an isothermal process, for heat recovery process, this energy part is cannot be used but to be wasted; however, it is a mutative temperature process for the mixture, which means we can use this energy reasonably, so that the heat loss for the mixture in condensing process can be evidently lower comparing to the pure fluids.

The comparison between the $\mathrm{T}-\mathrm{S}$ pictures of the pure and mixed working substance suggests that the match ability between the mixture and the heat source is much better because the evaporation process of the mixture is a mutative temperature process. In the evaporation process, the pinch point of temperatures comes in the inlet and outlet of the heat exchanger for the zeotropic mixture working fluids; but for the pure fluid, it comes in the bubble point - in the middle of the heat exchangerbringing bad effects on the design and operation of the exchanger.

Fig 8 (a), (b)show the change laws of the cycle characteristics including thermal cycle efficiency, exergy efficiency, net work and expansion ratio with mass fraction of R245ca in the mixture fluid in the basic cycle process. For the basic cycle process, by comparison, the thermal efficiency, exergy efficiency and the net work are lower but not much than the pure working fluid. The expansion ratio of the zeotropic mixture working fluids is less than the R227ea within the range of 0.1-0.8, while the expansion ratio of the zeotropic working fluids is always less than the R245ca, which is conducive to the economy of the system.

Fig.8(c), (d) show the change laws of the cycle characteristics including thermal efficiency, exergy efficiency, net work and expansion ratio with mass fraction of R245ca in the mixture fluid in the recovery heat process. We can conclude that the thermal efficiency, exergy efficiency, net work of the mixed substance, when the mass fraction of R245ca is 0.2-0.9, are higher than that of the pure fluids; and the mixture's expansion ratio is lower than the R227ea when the mass ratio of R245ca is 0.1-0.8, while the mixture's expansion ratio is lower than the R245ca all the time. That's because the heat recovery process, for the mixture, can recycle the latent heat of liqufaction of the fluids, and the temperature of point "a" can be lower than the sew temperature; for the pure substance, the temperature of point "a" cannot be lower than the dew temperature because its bubble temperature when condensing is the same as its dew temperature, that's why we cannot recycle its latent heat of liqufaction, leading its thermal efficiency to be lower than the mixture's. On the other hand, when the temperature of recovery point " $b$ " is higher than the bubble temperature of the mixture, the temperature of pinch point comes in the inlet of the evaporator, reducing the exergy loss of the evaporator and improving the matching ability between the mixture and the heat source. 


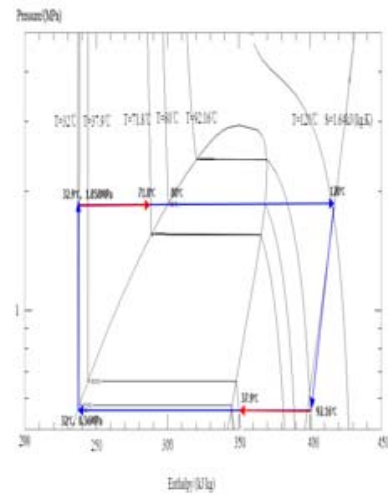

(a)

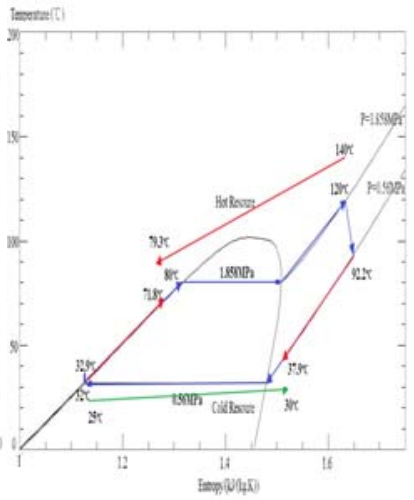

(b)

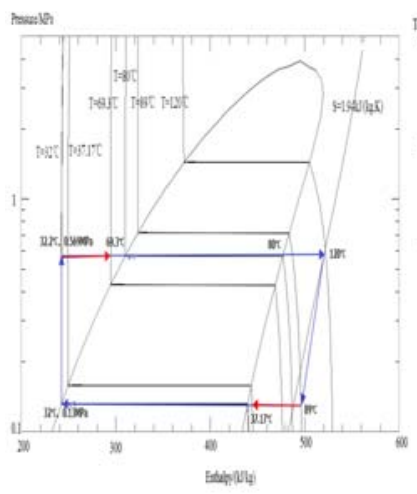

(a)

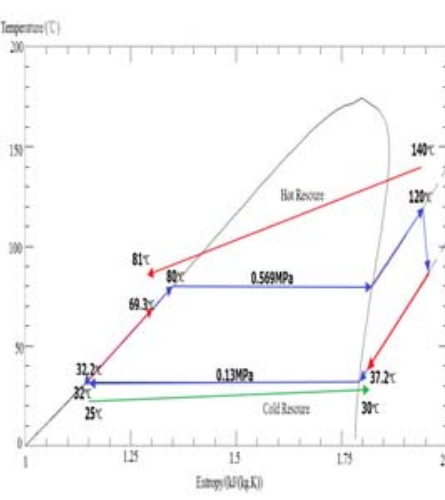

(b)

Fig 5 R227ea cycle process (a) $\mathrm{P}-\mathrm{H}$, (b) $\mathrm{T}-\mathrm{S}$

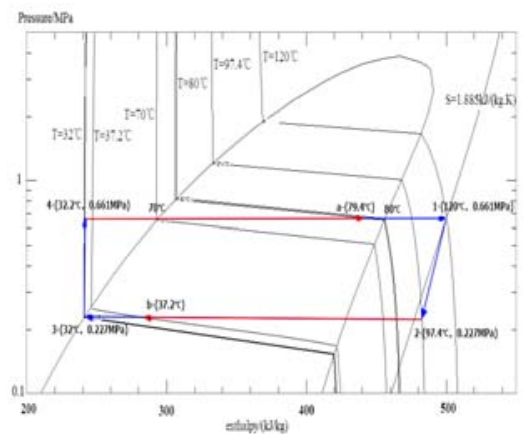

(a)
Fig 6 R245ca cycle process (a) $\mathrm{P}-\mathrm{H}$ diagram, (b) $\mathrm{T}-\mathrm{S}$

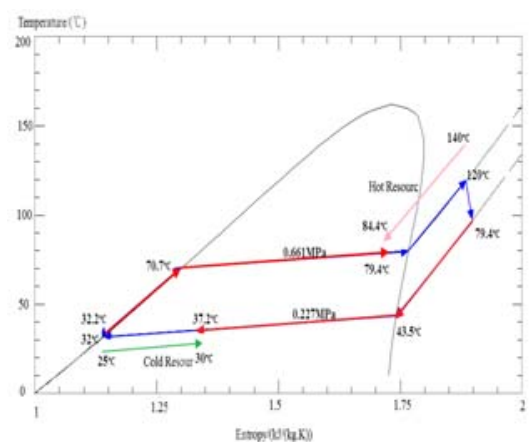

(b)

Fig 7 cyclic process diagram of mixture R227ea / R245ca (a) P-H, (b) T-S

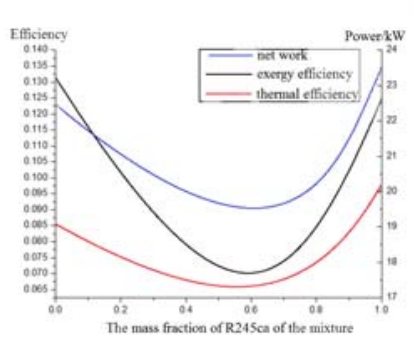

(a)

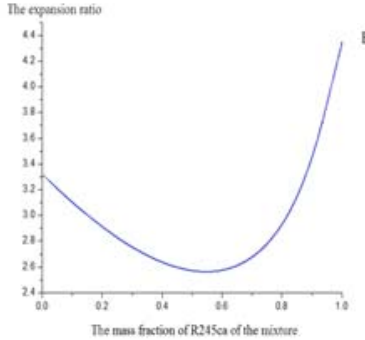

(b)

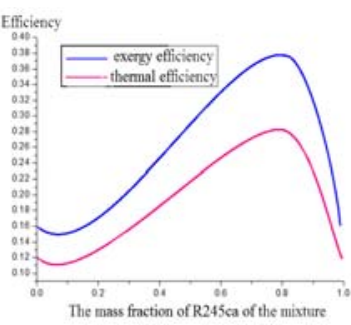

(c)

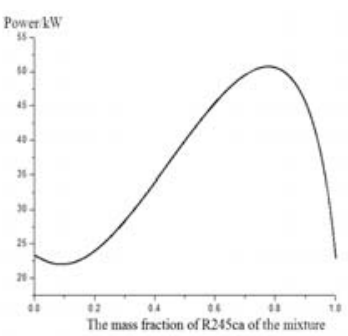

(d)

Fig8. Comparison of the pure and the mixture (a) the basic cycle (b) the expansion ratio of the basic cycle

(c) The cycle with IHX (d) the cycle with IHX

\section{Evaluations and Analysis of the Factors of the Zeotropic Working Fluids}

\section{Influence of the Temperature of the Heat Source:}

According to the mixture substance R245ca/R227ea, we studied the influence of the temperature of the heat source on the cycle characteristic, by taking 5 different working conditions - the temperatures were set as $120^{\circ} \mathrm{C}, 110^{\circ} \mathrm{C}, 100^{\circ} \mathrm{C}, 90^{\circ} \mathrm{C}, 80^{\circ} \mathrm{C}$, and the other conditions were kept as the same: the condensing temperature was $32^{\circ} \mathrm{C}$, evaporation temperature was $20^{\circ} \mathrm{C}$ lower than the heat source; the superheat was $0^{\circ} \mathrm{C}$. The Fig. 9 suggested that the higher the heat source temperature is, the better the cycle efficiency and cycle net work are. 


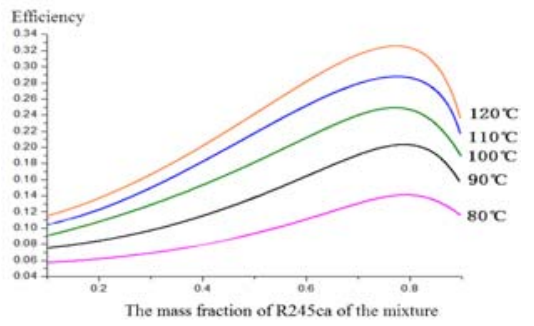

(a)

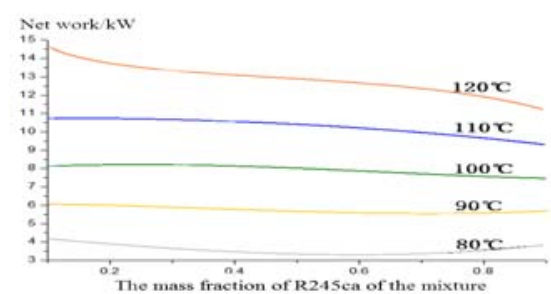

(b)

Fig.9. The influence of the heat source temperature

\section{Influence of the Evaporating Temperature:}

The heat source temperature was set as $180^{\circ} \mathrm{C}$, the mass flow of the substance $3 \mathrm{~kg} / \mathrm{s}$, and then we studied the influence of the evaporating temperature on the mixture's cycle characteristics, by taking 8 different working conditions-the temperatures were set as $130^{\circ} \mathrm{C}, 120^{\circ} \mathrm{C}, 110^{\circ} \mathrm{C}, 100^{\circ} \mathrm{C}, 90^{\circ} \mathrm{C}, 80^{\circ} \mathrm{C}$, $70^{\circ} \mathrm{C}, 60^{\circ} \mathrm{C}$ as the Fig. 10 shown,We found that the cycle efficiency and exergy efficiency becomes higher when the evaporating temperature goes higher. That's because the expansion work of unit substance increases as the evaporating temperature increases, making the cycle net work higher, so the thermal efficiency and the exergy efficiency go higher. The net work of the whole cycle, however, becomes higher first but lower later, and there exists a best evaporating temperature; because the cycle net work of unit substance is higher as the evaporating temperature higher, but the substance's mass flow of the system is smaller as the evaporating temperature higher. When the heat temperature is $180^{\circ} \mathrm{C}$ and the mass fraction of R245ca is between 0.2 and 0.9 , the cycle net work gets the higher when the evaporating temperature is $90^{\circ} \mathrm{Cthan}$ the other evaporating temperature, and gets the highest as the mass fraction taken as 0.9. As for the 0-0.2 mass fraction of the R245ca, nevertheless, the cycle net work is higher when the evaporating temperature is $100^{\circ} \mathrm{Cor} 110^{\circ} \mathrm{C}$ than that when the evaporating temperature is $90^{\circ} \mathrm{C}$. Because the decrease speed of the mass flow is smaller than the increase speed of the of the unit substance's cycle net work when the evaporating temperature is ranging from $90^{\circ} \mathrm{Cto} 100^{\circ} \mathrm{C}$. That's why he cycle net work is higher when the evaporating temperature is $100^{\circ} \mathrm{Cor} 110^{\circ} \mathrm{C}$ than that when the evaporating temperature is $90^{\circ} \mathrm{C}$, as for the $0-0.2$ mass fraction of the R245ca.

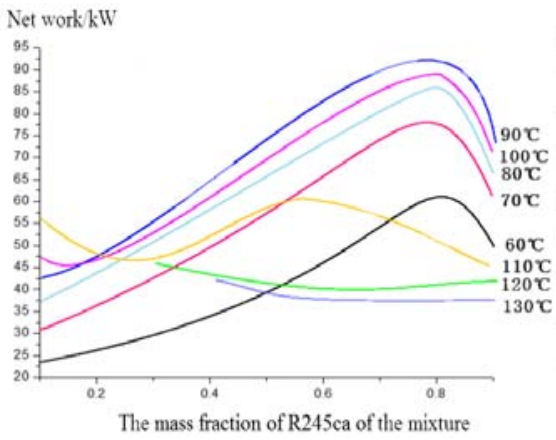

(a)

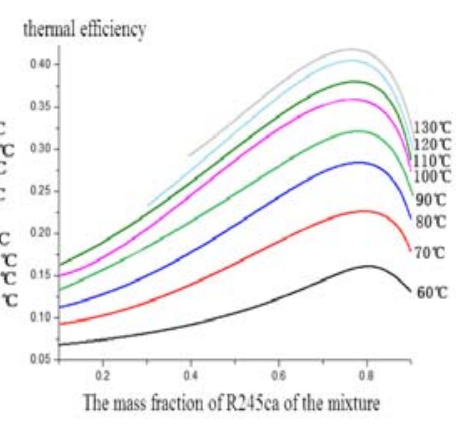

(b)

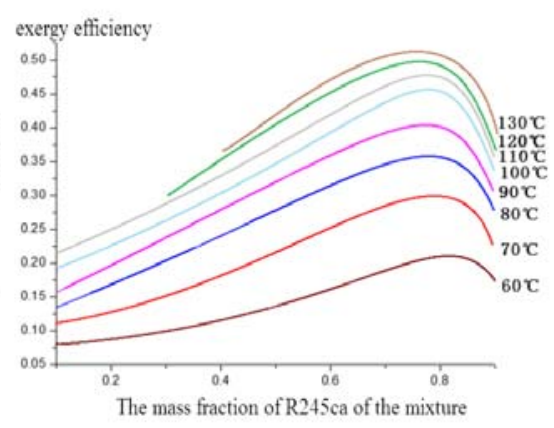

(c)

Fig.10. the influence of the evaporating temperature

\section{Influence of the Superheat}

The heat source temperature was set as $140^{\circ} \mathrm{C}$, the mass flow of the substance as $3 \mathrm{~kg} / \mathrm{s}$, the evaporating temperature as $80^{\circ} \mathrm{C}$, and then we studied the influence of the superheat on the mixture's cycle characteristics, by taking 11 different working conditions - the superheats were set as $0^{\circ} \mathrm{C}, 5^{\circ} \mathrm{C}, 10^{\circ} \mathrm{C}, 15^{\circ} \mathrm{C}, 20^{\circ} \mathrm{C}, 25^{\circ} \mathrm{C}, 30^{\circ} \mathrm{C}, 35^{\circ} \mathrm{C}, 40^{\circ} \mathrm{C}, 45^{\circ} \mathrm{C}, 50^{\circ} \mathrm{C}$. As the fig. 11 (a), (b)following shown, for the basic cycle process, the cycle efficiency and exergy efficiency decrease when the superheat 
increases, meaning that the superheat is bad for the basic cycle characteristics. As the fig.11(c), (d) following shown, however, for the cycle with IHX, the cycle efficiency goes higher when the superheat increases. The reason is that the recoverable heat energy increases as the superheat increases, making the thermal efficiency higher, but the cycle net work goes lower first and higher later. That's because the mass flow of the mixture goes lower but higher later as the superheat rising; but the expansion unit work keeps increasing. At first, the increasing rate of the expansion unit work is lower than the decreasing rate of the fluid's mass flow, making the cycle net work reduced as the superheat increased; however, the increasing rate of the expansion unit work becomes higher than the decreasing rate of the fluid's mass flow, making the cycle net work increased. Thus, there is a best superheat existing if we take the cycle net work as the aim.

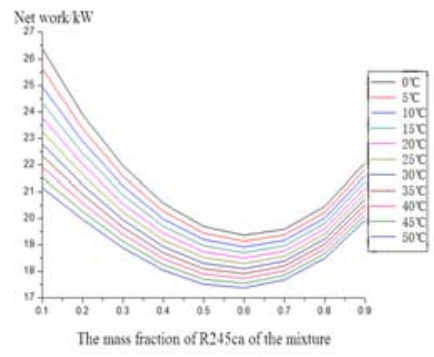

(a)

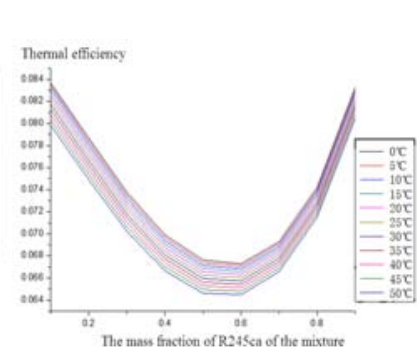

(b)

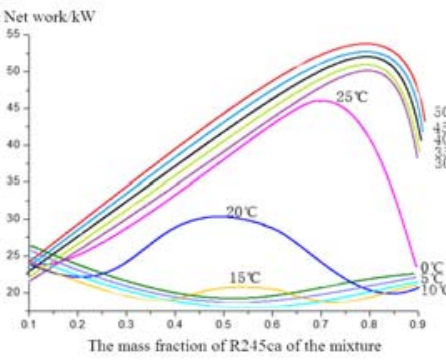

(c)

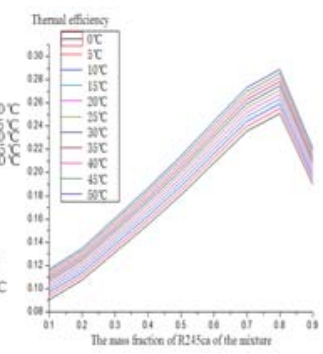

(d)

Fig.11. the influence of superheat (a)(b)the basic cycle (c)(d)the cycle with IHX

\section{The Combined Effects of the Evaporating Temperature and the Superheat}

In actual cycle, we need to take evaporating temperature and superheat together into consideration. The comparisons before are taken when there is only one influencing factor; in order to compare the influence of the evaporating temperature and the influence of the superheat at the same time, we set the same heat source, the temperature as $140^{\circ} \mathrm{C}$ and the mass flow as $3 \mathrm{~kg} / \mathrm{s}$, and different evaporating temperature, and then adjusting the superheat to make the point3's temperature keeps the same as $120^{\circ} \mathrm{C}$.As the Fig12 shown, the cycle with IHX's efficiency is increasing as the evaporating temperature increasing, and is independent from the superheat. The rise of the evaporating temperature gives rise to the mass flow of the mixture when the mass fraction of R245ca is between 0.2-0.9; but when the aim comes to the cycle net work, there still exists the best evaporating temperature. When the evaporating temperature is $80^{\circ} \mathrm{C}$ and the mass fraction of R245ca is 0.8 , there comes the highest cycle net work $50.8 \mathrm{~kW}$. So we can conclude that the evaporating temperature has more effect than the superheat on the cycle characteristics. Meanwhile, the Fig.12 shows that the range of the heat source is broaden by the utilization of the mixed substance, and by choosing the reasonable proportion, evaporating temperature and superheat, when the inlet and outlet temperatures are set, we can reach the aim of matching the heat source.

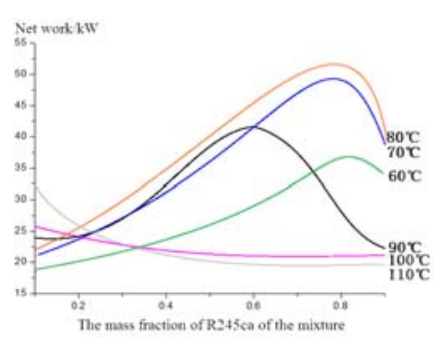

(a)

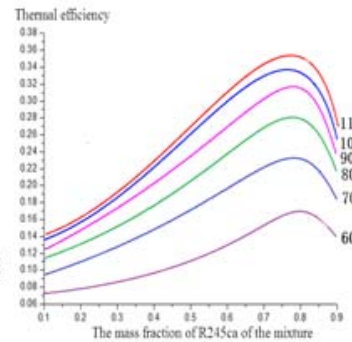

(b)

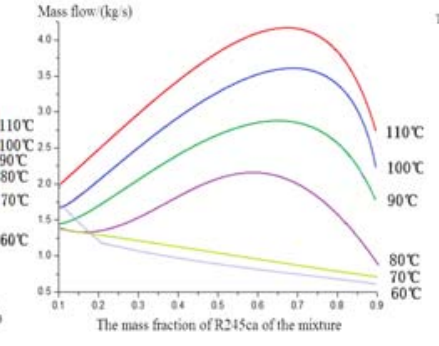

(c)

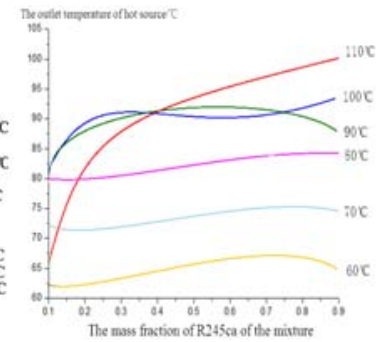

(d)

Fig.12. the combined effects of the evaporating temperature and the superheat 


\section{Conclusions}

When the ORC system takes the pure fluid as the cycle substance, the phase change process is an isothermal process, so its match ability with the heat source is not good; however, when taking the zeotropic working fluids, the phase change process is a thermal changing process, so its match ability with the heat source is pretty good, and it can take good advantage of its latent heat of liquefaction in the cycle with IHX, rising the thermal efficiency and exergy efficiency. This paper programs by REFPROP, and models by ASPEN PLUS for verification, which improves the accuracy of the results. This paper takes R227ea and R245ca as the component of the zeotropic working fluid, by changing the fraction of R245ca to get the results, and then compared with the pure working fluid. The conclusions as follows:

(1) As for the basic cycle process, the thermal efficiency, exergy efficiency and cycle net work of the mixture working fluid are lower but not much lower than those of the pure working fluid; the expansion ratio of the mixture ,when the mass fraction of R245ca is between 0.1 and 0.8 in the mixture, is lower than that of the R227ea's expansion ratio, and the expansion ratio of the mixture is lower than that of R245ca all the time, benefiting the economy of the system.

(2) As for the cycle with IHX, the thermal efficiency, exergy efficiency and cycle net work of the mixture working fluid, when the mass fraction of R245ca is between 0.2 and 0.9 in the mixture are higher than those of the pure; the expansion ratio of the mixture, when the mass fraction of R245ca is between 0.1 and 0.8 in the mixture, is lower than that of the pure R227ea, and the expansion ratio of the mixture is lower than that of R245ca all the time. In the evaporating process, the pinch point temperature appears in the inlet and outlet of the heat exchanger when the cycle substance is the mixture; it appears in the bubble point of the pure when the cycle substance is the pure- in the middle of the heat exchanger, which is bad for the design and operation of the heat exchanger.

(3) As for the zeotropic working fluids, the higher the heat source temperature is, the higher the cycle thermal efficiency and cycle net work are. But that's not mean that the higher the heat source temperature the better the results are. Too high the temperature usually brings decomposition to the mixture. And the lower the cold source's temperature is, the higher the cycle thermal efficiency and the cycle net work are.

(4) As the evaporating temperature increased, the cycle thermal efficiency and THE exergy efficiency of the zeotropic working fluids increase, but the cycle net work increases first and decreases later, meaning that there exists a best evaporating temperature. The cycle efficiency and exergy efficiency decrease when the superheat increases for the basic cycle process, meaning that the superheat is bad for the basic cycle characteristics, however, the cycle efficiency goes higher but the cycle net work goes higher first and lower later when the superheat increases for the cycle with IHX. The influence of evaporating temperature has higher priority than that of the superheat on the cycle, thus, we should choose the evaporating temperature first when we build the ORC with the zeotropic working fluids.

\section{References}

[1] You-Rong Li, Mei-Tang Du. Energy 77 (2014) 509-519.

[2] Zhenhua Kang, Jialing Zhu. Applied Thermal Engineering 89 (2015) 323-331.

[3] M. Chys, M. van den Broek. Energy 44 (2012) 623-632.

[4] Jian Zhanga, Hongguang Zhang. Energy Conversion and Management 84 (2014) 282-294.

[5] Florian Heberle, Markus Preißinger. Renewable Energy 37 (2012) 364-370.

[6] Baomin Dai , Chaobin Dang. international journal of refrigeration 56 (2015) 1-1 4.

[7] J.G. Andreasen, U. Larsen, T .Energy 73 (2014) 204-213. 